\title{
Membangun Identitas Sosial dalam Organisasi Mahasiswa Pascasarjana
}

\author{
Building Social Identity in Postgraduate Student Organizations
}

\author{
Oleh : \\ Imam Faisal Hamzah ${ }^{1}$ \\ Charis Agoha ${ }^{2}$ \\ Azolla Silviani ${ }^{3}$
}

\begin{abstract}
ABSTRAK
Organisasi Mahasiswa Pascasarjana merupakan organisasi yang terdiri dari bermacam latar belakang etnis, agama, hingga organisasi masyarakat. Tujuan penelitian ini adalah mendapatkan dinamika dalam membangun identitas sosial pada pengurus Organisasi Mahasiswa Pascasarjana. Penelitian ini menggunakan metode penelitian kualitatif dengan pendekatan fenomenologis. Pengambilan data dilakukan melalui wawancara semi terstruktur terhadap tiga orang subjek yang merupakan pengurus aktif organisasi tersebut yang berasal dari etnis yang berbeda. Hasil penelitian ini menunjukan bahwa kesetaraan dalam posisi diperlukan untuk membangun identitas sosial pada organisasi mahasiswa pascasarjana dalam organisasi yang terdiri dari berbagai macam latar belakang etnis, hal tersebut dapat muncul dalam upaya-upaya seperti keterbukaan untuk menerima kritik dan masukan jika ada perilaku yang kurang sesuai, membuka ruang komunikasi, dan juga perkembangan pola pikir sebagai mahasiswa pascasarjana. Kesimpulan dari penelitian ini adalah identitas etnis melebur menjadi identitas sebagai satu organisasi, hal tersebut dipengaruhi oleh beberapa faktor seperti latar belakang keluarga yang multi-etnis, kompleksitas budaya dari daerah asalnya, dan pengalaman berinteraksi dengan etnis lain.
\end{abstract}

Kata Kunci: Etnis; Identitas Sosial; Organisasi Mahasiswa Pascasarjana

\begin{abstract}
Postgraduate Student Organizations are organizations consisting of various ethnic, religious, and community organizations. The purpose of this research is to get dynamics in building social identity in the members of the Postgraduate Student Organization. This study uses qualitative research methods with a phenomenological approach. Data retrieval is done through semi-structured interviews of three subjects who are active organizers of the organization from different ethnic groups. The results of this study indicate that equality in positions is needed to establish social identity in the Postgraduate Student Organizations in organizations consisting of various ethnic backgrounds, this can arise in efforts such as openness to accept criticism and input if there are inappropriate behaviors, open the communication room, and also the development of the mindset as a graduate student. The conclusion of this study is that ethnic identity fuses into identity as an organization, it is influenced by several factors such as multi-ethnic family background, cultural complexity of the area of origin, and experience of interacting with other ethnic groups.
\end{abstract}

Keywords:Ethnic Identity; Postgraduate Student Organization; Social Identity

\footnotetext{
${ }^{1}$ Fakultas Psikologi - Universitas Muhammadiyah Purwokerto, imamfaisalh@ump.ac.id

${ }^{2}$ Sekolah Kristen Logos Surabaya,ch.agoha@gmail.com

${ }^{3}$ Fakultas Psikologi, Universitas Gadjah Mada, azolla.vivian@gmail.com 
IMAM FAISAL HAMZAH, CHARIS AGOHA, \& AZOLLA

SILVIANI,Membangun Identitas Sosial dalam Organisasi Mahasiswa

Pascasarjana

\section{PENDAHULUAN}

Organisasi mahasiswa merupakan organisasi yang dinamis. Di mana mahasiswa dapat mengaktualisasikan minat dan bakatnya termasuk idealismenya. Sehingga mahasiswa tidak hanya memeroleh input akademis atau hardskill saja, tetapi juga terasah kemampuan softskill-nya. Pengalaman-pengalaman dalam organisasi inilah yang kelak diperlukan ketika terjun dalam dunia kerja. Salah satunya adalah mengelola perbedaan yang ada dalam internal organisasi mahasiswa itu sendiri.

Tidak dipungkiri bahwa organisasi mahasiswa terdiri dari bermacammacam karakter, kepribadian, hingga identitas. Hal itu karena perguruan tingi itu sendiri merupakan tempat berkumpulnya bermacam-macam latar belakang mahasiswa, baik itu latar belakang etnis, agama, organisasi sosial, maupun status sosial ekonomi. Keberagaman identitas sosial ini dapat menjadi potensi negatif maupun positif. Negatif jika justru keberagaman tersebut justru menghambat kinerja organisasi, dan positif jika justru keberagaman tersebut dapat dikelola dengan baik untuk kemajuan organisasi.

Pada hakikatnya, individu itu sendiri terlahir dalam suatu kelompok sosial. Oleh sebab itu, keanggotaan yang diturunkan dalam suatu kelompok sosial menjadikan individu memperoleh identitas sosial, misalnya agama, etnis, organisasi sosial, dan sebagainya. Tajfel (1982) mendefinisikan "Identitas Sosial" sebagai bagian konsep diri individu-individu yang berasal dari pengetahuan mereka terhadap keanggotaannya dalam suatu kelompok sosial berdasarkan keterikatan nilai-nilai dan emosi. Misalnya "Saya adalah orang Indonesia."

Demikian pula halnya pada lingkup organisasi, individu memperoleh dampak identitas sosial yang positif melalui peningkatan self-esteem ketika masuk dalam suatu organisasi. Hennesy dan West (1999) melakukan penelitian pada layanan kesehatan rumah sakit "National Health Service" (NHS) di Inggris, untuk menguji Teori Identitas Sosial di wilayah organisasi. Penelitian yang dilakukan kepada 112 partisipan dari 17 kelompok kerja yang berada dalam organisasi kesehatan ini menunjukkan bahwa individu yang mengidentifikasikan dirinya dengan kelompok kerja berkorelasi secara positif terhadap evaluasi in-group favoritism (Hennesy \& West, 1999). Jadi, individu menjadi meningkat harga dirinya ketika berada dalam kelompok kerja (organisasi) seraya memelihara dan mempertahankan keadaan tersebut.

Permasalahannya sekarang, organisasi secara khusus terdiri dari berbagai macam individu yang memiliki identitas sosial di dalamnya, misalnya saja etnis. Sejarah mencatat salah satu contoh ketika perang dunia ke-2, Inggris menjadi masyarakat yang multi-etnis oleh karena imigran Jamaika masuk dan tinggal disana. Diskriminasi etnis pun terjadi dalam lingkup organisasi seperti di perguruan tinggi, perusahaan, stasiun radio bahkan pada layanan kesehatan publik (Kenny \& Briner, 2010; Weech-Maldonado, Dreachslin, \& Kathryn, 2002). 
Ketimpangan juga terjadi pada karyawan di organisasi ketika melakukan pelayanan karena munculnya sikap dan prasangka negatif terlebih dahulu kepada masyarakat beda etnis, misalnya pada kepolisian di New Zealand (Jaeger \& Vitalis, 2005).

Berhadapan dengan berbagai macam kepentingan etnisitas individu, maka organisasi perlu pula menyadari esensi utamanya, yakni sebagai intrumen dalam mencapai suatu tujuan. Organisasi yang tinggi keberagaman etnisnya sangat dimungkinkan terjadi sentimen antar kelompok etnis. Namun dibalik permasalahan itu, organisasi perlu berjuang untuk mengesampingkan kepentingan kelompok etnis tertentu demi tujuan yang lebih besar, yakni tujuan organisasi. Lalu kini pertanyaannya bagaimana organisasi mengimplementasikan esensi terhadap tujuannya ketika berhadapan dengan diversitas etnis di dalamnya?

Berdasarkan pertanyaan di atas, maka menjadi menarik untuk melakukan penelitian mengenai interaksi diversitas etnis pada organisasi mahasiswa, khususnya organisasi mahasiswa pascasarjana. Organisasi kemahasiswaan tersebut terdiri dari mahasiswa pascarsarjana dari berbagai daerah di Indonesia. Oleh keberagaman etnis tersebut seringkali disebut sebagai "miniatur Indonesia". Penelitian ini bertujuan untuk memeroleh makna identitas etnis dalam interaksi individu pada organisasi mahasiswa pascasarjana.

\section{METODE PENELITIAN}

Penelitian menggunakan metode penelitian kualitatif dengan menggunakan pendekatan fenomenologis. Di mana pendekatan fenomenologis merupakan pendekatan kualitatif yang didasarkan pada filsafat fenomenologi. Lathief (2008) menjelaskan bahwa fenomenologi itu sendiri adalah sebuah upaya untuk mendeskripsikan suatu objek sebagaimana objek tersebut menampakan diri ke dalam kesadaran.

\section{Fokus Penelitian}

Fokus utama penelitian ini adalah mendapatkan dinamika dalam membangun identitas sosial pada pengurus organisasi mahasiswa pascasarjana.

\section{Informan Penelitian}

Informan dalam penelitian ini adalah 3 pengurus aktif organisasi mahasiswa pascasarjana yang dilihat dari latar belakang etnis berbeda.

\section{Metode Pengumpulan Data}

Pengumpulan data dilakukan dengan wawancara semi struktur terhadap subjek-subjek penelitian.

\section{Metode Analisis Data}

Data yang terkumpul kemudian dianalisis menggunakan metode eksplikasi data yang meliputi lima tahap (Subandi, 2009). Pertama, memperoleh pemahaman data sebagai suatu keseluruhan. Kedua, menyusun DFI (Deskripsi Fenomena Individual). Ketiga, mengidentifikasi episode-episode umum di setiap 
IMAM FAISAL HAMZAH, CHARIS AGOHA, \& AZOLLA SILVIANI,Membangun Identitas Sosial dalam Organisasi Mahasiswa

Pascasarjana

DFI. Keempat, ekplikasi tema-tema dalam setiap episode. Kelima, sintesis dari penjelasan tema-tema dalam setiap episode.

\section{HASIL DAN PEMBAHASAN}

Peneliti mendapatkan tiga pengurus organisasi mahasiswa pascasarja yang bersedia untuk menjadi subjek, seperti pada tabel 1 sebagai berikut:

Tabel 1. Informasi Mengenai Subjek

\begin{tabular}{llll}
\hline & MS & Yb & IF \\
\hline Asal & Sulawesi & Tangerang & Sulawesi \\
\hline Etnis & $\begin{array}{l}\text { "Sulawesi Barat" } \\
\text { (Tidak disebutkan } \\
\text { spesifik etnisnya) }\end{array}$ & Betawi & Bugis \\
\hline Fakultas & Psikologi & FISIP & MIPA \\
\hline Jabatan di & Humas & FISH & Humas \\
Organisasi & & & \\
\hline
\end{tabular}

Setelah memeroleh tema-tema umum maupun tema-tema unik dari masing-masing subjek dari proses Deskripsi Fenomena Individual (DFI) diperoleh sintesis yang terbagi tiga episode. Peneliti menggambarkannya dalam bentuk tabel 2 berikut.

Tabel 2. Sisntesis Tema

\begin{tabular}{|c|c|c|c|c|}
\hline No & Hal & MS & $\mathbf{Y b}$ & IF \\
\hline \multicolumn{5}{|c|}{ Episode Latar Belakang Indvidu } \\
\hline 1 & Pengalaman S1 & $\begin{array}{l}\text { Jarak sosial yang } \\
\text { rendah }\end{array}$ & $\begin{array}{c}\text { Tanggung jawab } \\
\text { berorganisasi }\end{array}$ & $\begin{array}{l}\text { Belum pernah } \\
\text { berorganisasi }\end{array}$ \\
\hline 2 & $\begin{array}{l}\text { Latar belakang } \\
\text { budaya }\end{array}$ & Sulawesi barat & Tangerang Betawi & $\begin{array}{l}\text { Makasar dengan } \\
\text { keturunan Bugis } \\
\text { dan Padang }\end{array}$ \\
\hline 3 & $\begin{array}{l}\text { Interaksi } \\
\text { dengan etnis } \\
\text { lain }\end{array}$ & $\begin{array}{l}\text { Pengalaman } \\
\text { berinteraksi } \\
\text { dengan etnis lain } \\
\text { di Jawa }\end{array}$ & $\begin{array}{l}\text { Pemahaman } \\
\text { melalui observasi } \\
\text { dan komunikasi } \\
\text { langsung }\end{array}$ & $\begin{array}{l}\text { Melakukan } \\
\text { perbandingan } \\
\text { dengan budaya } \\
\text { lain }\end{array}$ \\
\hline
\end{tabular}

Episode Kerterlibatan dalam Organisasi Mahasiswa Pascasarjana

4 Tujuan $\quad$ Penasaran $\quad$ Menyukai $\quad$ Mendapatkan




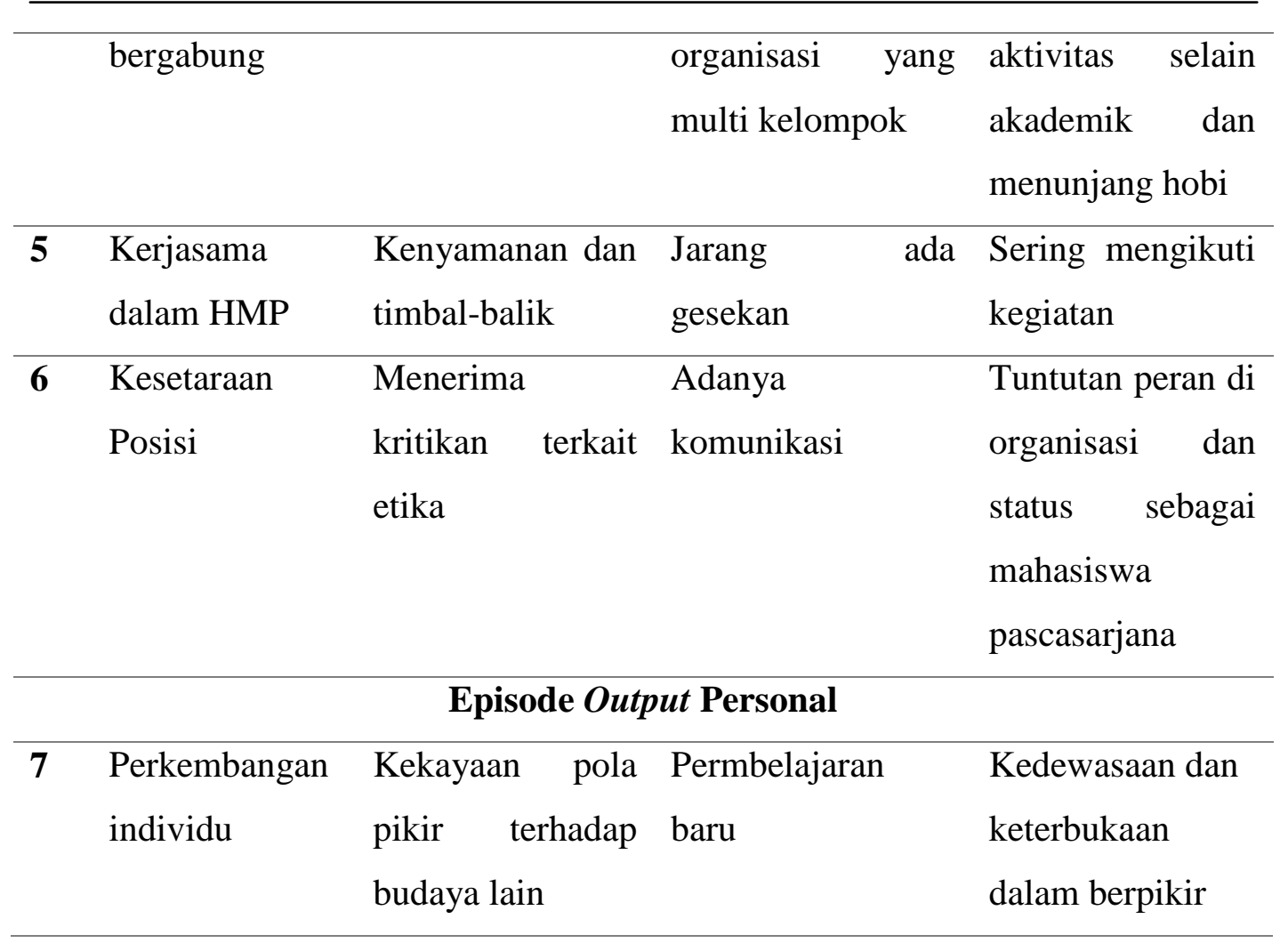

\section{Episode Latar Belakang Indvidu}

Latar belakang individu memiliki pengaruh dalam interaksi individu dengan individu dari etnis lain. Pengalaman dari segi latar belakang budaya, misalnya seperti kompleksitas etnis di pulau, pengalaman pernah menjadi minoritas etnis, dan orang tua yang berbeda etnis dapat memengaruhi individu dalam berinteraksi dengan etnis lain. Selain itu pengalaman individu dalam berogranisasi di S1 juga turut menyumbang pengalaman berogranisasi subjek ketika bergabung di HMP atau berinteraksi dengan etnis lain.

Ketika subjek berinteraksi dengan etnis lain, banyak yang mengaku mengalami shock karena perbedaan budaya dibandingkan dengan budaya asalnya. Subyek banyak melakukan kontak langsung, observasi, komunikasi, maupun melakukan perbandingan antar budaya untuk dapat lebih menerima budaya lain di luar budayanya sendiri.

Episode ini dibagi ke dalam tiga hal, yaitu pengalaman ketika S1, latar belakang budaya, dan interaksi dengan etnis lain. Pada pengalaman ketika S1. Masing-masing subjek memiliki pengalaman yang berbeda. MS pernah aktif di Majelis Perwakilah Mahasiswa. Namun, bagi MS kultur di kampus asalnya di Makasar berbeda ketika MS kuliah pascasarjana di Yogyakarta, di Makasar jarak sosial antara dosen dan mahasiswa yang cenderung tidak berjarak. MS menyampaikannya sebagai berikut: 
IMAM FAISAL HAMZAH, CHARIS AGOHA, \& AZOLLA

SILVIANI,Membangun Identitas Sosial dalam Organisasi Mahasiswa

Pascasarjana

"[perbedaan antara kultur di S1 asal dan di S2] Oh ya jelas, kalau dari aspek culture ya, ada. Kan kalau di sana. Kalau budaya kuliah di sana tho, kedekatan mahasiswa dengan dosen, dosennya yang mendekat ke mahasiswa, kalau di sini kan kalau saya perhatikan kaya ini ya, beda ya? Mahasiswa yang ngejar dosen gitu. Kalau di sana beda. Kemudian apa lagi ya? Untuk masalah ini, masalah bobot pendidikan dan fasilitasnya di sini justru lebih bagus dari pada di sana. Kualitas pendidikannya bagus ya." (MS)

Berbeda dengan MS, Yb sewaktu kuliah S1 pernah menjabat dalam organisasi internal sebagai wakil menteri di BEM. Dalam lingkup eksternal, Subjek juga pernah mengikuti PMII dan GMNI. Akhirnya pada jenjang S2 Subjek mengikuti organisasi mahasiswa pascasarjana. Pengalaman berorganisasi tersebut menumbuhkan pola pikir dan mampu memposisikan dirinya sesuai dengan tanggungjawab di organisasi. Berbeda dengan MS dan $\mathrm{Yb}$, IF justru belum pernah mengikuti organisasi selama berkuliah di S1. IF bergabung dengan organisasi mahasiswa pascasarna untuk merasakan pengalaman selain menjalankan pendidikan formal.

Selain pengalaman ketika berkuliah S1, latar belakang budaya dan pengalaman berinteraksi dengan etnis lain juga memberikan warna. MS berasal dari Sulawesi Barat, Yb beretnis Betawi, dan IF merupakan keturunan Bugis dan Padang. Sulawesi Barat, bagi MS, merupakan wilayah yang multi etnis. Bahkan di kampusnya dahulu, kompleksitas etnisnya lebih dibandingkan kampus di Jawa.

Pengalaman $\mathrm{Yb}$ berinteraksi dengan etnis lain yaitu ketika menjadi santri di sebuah pondok pesantren yang lingkungannya Sunda, tetapi mengaji dengan kitab berbahasa Jawa. Hal ini menjadikan Yb merasa menjadi minoritas. Setelah itu kuliah dan tinggal di kos yang terdiri dari beragam karakter orang serta belajar bahasa Inggris di Pare Kediri, sama seperti MS. Sedangkan IF, meskipun dibesarkan dalam budaya Makasar, tetapi orang tuanya merupakan campuran Bugis dan Padang.

Latar belakang etnis yang kompleks dan berinteraksi dengan budaya dari etnis lain tersebut tampaknya menjadi modal bagi MS, Yb, dan IF. Mereka terbiasa dengan perbedaan etnis, ketika berinteraksi dengan individu dari latar belakang etnis yang berbeda-beda.

\section{Episode Keterlibatan dalam Organisasi Mahasiswa Pascasarjana}

Subjek bergabung sebagai anggota Organisasi Mahasiswa Pascasarjana dengan tujuan yang berbeda-beda, seperti karena penasaran (MS), tertarik dengan organisasi multi identitas (Yb), maupun sekedar untuk menunjang hobi (IF). Meskipun begitu, HMP menawarkan sesuatu yang lain bagi anggotanya. 
HMP merupakan media yang efektif untuk melakukan kontak antar etnis dalam lingkungan mahasiswa pascasarjana. Kontak ini dapat berbentuk kerja sama seperti melakukan aktifitas maupun saling membantu dalam kegiatan. Selain itu, adanya kesetaraan dalam organisasi dapat menunjang kontak antar etnis dalam HMP. Kontak tersebut dapat berupa menerima kritikan secara terbuka dari pihak lain, tidak menyukai intimidasi, maupun status sebagai mahasiswa pascasarjana mmampu mendukung terjadinya kontak.

Yb misalnya, pandangannya yang semula tampak mencurigai beralih menjadi memahami oleh karena adanya komunikasi. Dari komunikasi, Yb mengetahui kebiasaan berinteraksi dari etnis lain (Makasar atau Madura) sehingga $\mathrm{Yb}$ dapat menyesuaikan sikap dan tindakannya. Subjek juga merasa tidak setuju adanya intimidasi terhadap etnis maupun agama minoritas dari kelompok mayoritas. Sebab dalam konteks perbedaan terdapat persepsi dan refleksi masing-masing yang perlu dipahami dan diakomodasikan.

IF mengaku ketika awal bergabung, tidak memiliki kenalan, kecuali ketua organisasinya yang memang mahasiswa pascasarjana dari Fakultas MIPA.

"Awalnya memang saya tidak banyak mengenal, ketua tidak kenal, wakil tidak kenal, tapi kebetulan ketua nya juga dari fakultas MIPA jurusan Matematika. Jadi ya kenal dari banyak kegiatan, setiap acara ya kita hadir, ada rapat ya kita hadir ya akhirnya cair sendiri ya pokoknya intinya sih itu aja kalau ada kegiatan sering-sering aja hadir nanti juga kenal sendiri." (IF)

IF jadi lebih mengenal anggota lain dengan sering mengikuti kegiatan yang diselenggarakan oleh Organisasi Mahasiswa Pascasarjana. Sedangkan MS, karena merasa nyaman dengan orang-orang di Organisasi Mahasiswa Pascasarjana dan para anggota dapat bekerja sama dengan baik sehingga ada hubungan timbal balik antar anggota.

Semua hal tersebut, ditunjang dengan adanya kesetaraan posisi di dalam melakukan relasi. MS mengaku dapat menerima kritikan terkait etika dari anggota lain. MS lebih menyukai jika orang lain lebih asertif, sehingga MS menjadi lebih mengetahui mana yang seharusnya dilakukan dan mana yang tidak seharusnya dilakukan. Bagi $\mathrm{Yb}$, adanya komunikasi menjadi penting untuk lebih memahami perbedaan satu sama lain dan bukan untuk saling mengintimidasi.

"...Beda kayak dulu saya masih di S1 sulit untuk memahami orang-orang luar, seperti lingkungan kita. Dulu kuliah itu lihat orang tuh, wah lu kayak gini... setelah lama dialog, komunikasi... akhirnya kita jadi saling memahami. Misalnya kayak orang Madura atau Makasar itu bersuara kasar, mungkin kalau orang yang belum paham pasti bisa chaos gitu... tapi karena saya sudah paham karakter jadi bisa maklumi, enjoy aja..." (Yb)

Peran di bidang Humas, membuat IF terdorong untuk bisa lebih dekat dengan siapapun. Selain itu, status sebagai mahasiswa pascasarjana 
IMAM FAISAL HAMZAH, CHARIS AGOHA, \& AZOLLA

SILVIANI,Membangun Identitas Sosial dalam Organisasi Mahasiswa

Pascasarjana

menjadikannya untuk tidak terlalu menjadikan perbedaan budaya sebagai penghalang.

\section{Episode output personal}

Pengalaman yang kompleks berinteraksi antar etnis dalam lingkungan organisasi mahasiswa pascasarjana, menumbuhkan suatu pemahaman pola pikir yang lebih kaya (MS), memunculkan pembelajaran baru (Yb), kedewasaan, dan keterbukaan dalam berpikir (IF) mengani etnis dari budaya lain dalam organisasi.

$\mathrm{Yb}$ merasa bahwa akomodasi terhadap perbedaan berfungsi sebagai pembelajaran terhadap individu dari etnis lain. Tidak hanya dari satu pihak, tetapi justru kedua pihak sekaligus dapat saling memahami karakteristik etnis satu sama lain. Oleh karena itu, perlu ada ruang untuk saling berkomunikasi satu sama lain.

Indonesia merupakan salah satu negara yang memiliki kecenderungan ke arah budaya yang kolektif dibandingkan individualis, hal tersebut dapat ditunjukan melalui adanya interdependensi, tujuan kelompok, dipengaruhi oleh norma, dan mengutamakan kelangsungan hubungan maupun kebutuhan orang lain (Triandis dan Bhawuk, 1997). Hal ini pun terlihat dalam organisasi mahasiswa pascasarjana di salah satu Perguruan Tinggi, di mana partisipan dalam penelitian ini berusaha untuk menjaga hubungan mereka daripada mengutamakan ego budaya sendiri, misalnya pada subyek MS yang justru senang ditegur karena etika perilakunya yang tidak sesuai.

Sebagai negara yang kolektif, maka kecenderungan ke arah adanya kategorisasi sosial pun hampir tidak tampak (Pichlera, Varma, \& Budhwar, 2012). Hal ini dikarenakan individu-individu dalam organisasi mahasiswa pascasarjana memiliki kesamaan sebagai anggota organisasi, sebagai mahasiswa Pascasarjana maupun sebagai bangsa Indonesia sendiri. Adanya perbedaan dalam organisasi justru dianggap sebagai sebuah peluang untuk membangun jaringan, misalnya pada subjek Yb yang melihat perbedaan itu untuk memanfaatkannya jika ada kepentingan penelitian yang dilakukan oleh subjek.

Hal tersebut mendukung penelitian yang dilakukan oleh Pichler, Varma, dan Budhwar (2012) di mana kategorisasi sosial tidak cukup berlaku pada negara-negara yang memiliki kecenderungan kolektif, sehingga seringkali individu dari out group justru dianggap sebagai bagian dari in group. Di sisi lain, subjek dalam penelitian ini mengemukakan bahwa mereka tidak menyukai karakter seseorang sebagai individu bukan sebagai anggota dari suatu kelompok atau bagian dari suatu etnis tertentu.

Ada banyak hal yang kemudian memengaruhi individu untuk dapat memiliki sikap yang lebih terbuka terhadap individu dari budaya lain. Penelitian 
ini menunjukan bahwa salah satu yang menjadi faktor terbukanya individu dalam organisasi mahasiswa pascasarjana terhadap etnis lain adalah pengaruh orang tua yang berbeda etnis, seperti ditunjukan oleh subyek IF. Hal ini senada dengan penelitian yang dilakukan oleh Faturochman, Kurnianingsih, Kurniastuti, \& Fathoni (2011) di mana individu yang berasal dari orang tua yang berbeda etnis, memiliki tingkat prasangka yang rendah atau tingkat kepercayaan (trust) yang lebih tinggi dibandingkan dengan individu yang orang tuanya berasal dari etnis yang sama.

Selain itu, faktor pengalaman seperti ditunjukan subyek $\mathrm{Yb}$ dan juga lingkungan etnis yang kompleks seperti ditunjukan oleh subyek MS juga dapat memperkaya sikap individu terhadap individu dari budaya lain. Modal ini sangat penting bagi individu untuk berinteraksi dengan kelompok kultur yang lain (Panggabean, Tjitra, dan Murniati, 2014).

Secara keseluruhan, adanya kontak sosial dan ruang untuk berkomunikasi sebagai proses untuk membangun identitas sosial pada organisasi mahasiswa pascasarjana. Kontak sosial yang dikemukakan oleh Allport (dalam Brewer \& Geartner, 2003) mensyaratkan adanya kesetaraan kelompok, kerjasama, tujuan bersama, dan dukungan otoritas dapat diwujudkan dalam organisasi seperti organisasi mahasiswa pascasarjana.

Tidak ada individu dengan identitas etnis yang menonjolkan diri lebih unggul dibandingkan lainnya menunjukan kesetaraan tersebut, kemudian adanya kerjasama dalam kinerja organisasi, tujuan bersama yang ingin dicapai melalui organisasi, dan dukungan dari otoritas perguruan tinggi turut menyumbang kontribusinya terhadap terwujudnya kontak sosial dalam organisasi. Kontak sosial inilah yang kemudian membentuk satu identitas baru sebagai identitas organisasi.

Organisasi sebagai kelompok identitas sosial memiliki makna psikologis bagi semua individu yang ditandai dengan koordinasi sehingga perilaku individu diatur dan terstruktur daripada idiosinkratik, kemudian memiliki tujuan yang diarahkan, sehingga struktur ini berorientasi pada suatu hasil tertentu (Statt dalam Haslam, 2004)

\section{KESIMPULAN}

Banyak faktor yang memengaruhi adanya interaksi antar etnis dalam organisasi mahasiswa pascasarjana. Adanya latar belakang keluarga yang berbeda etnis, pengalaman individu bersentuhan dengan kelompok lain, maupun kompleksitas etnis di mana individu tinggal. Perbedaan etnis menjadi sesuatu yang sangat menunjang kinerja organisasi jika disertai adanya syarat-syarat terjadinya kontak sosial sehingga memungkinkan juga terbentuknya identitas baru sebagai bagian dari organisasi itu sendiri.

\section{DAFTAR PUSTAKA}


IMAM FAISAL HAMZAH, CHARIS AGOHA, \& AZOLLA

SILVIANI,Membangun Identitas Sosial dalam Organisasi Mahasiswa

Pascasarjana

Brewer, M.B. dan Gaertner, S.L. (2003). Toward Reduction of Prejudice : Intergroup Contact and Social Categorization. Dalam Brown, R. dan Gartner, S.L. Blackwell Handbook of Social Psychology : Intergroup Processes. Victoria : Blackwell Publishing

Faturochman, Kurnianingsih, S., Kurniastuti, I., dan Fathoni, N.S. (2011). The Role of Inter Ethnic Marriage on Trust and Caution. Jurnal Psikologi, 38 (1), 73-81

Hennesy, J., \& West, M. A. (1999). Intergroup Behavior in Organizations: A Field Test of Social Identity Theory. Small Group Research, 30(3), 361382.

Haslam, S.A. (2004). Psychology in Organization : The Social Identity Approach. California : Sage Publication

Jaeger, S., \& Vitalis, T. (2005). Ethnic Diversity in the New Zealand Police: Staff Perspectives. Equal Opportunities International, 24(1), 14-27

Kenny, E. J., \& Briner, R. B. (2010). Exploring Ethnicity in Organizations. Equality, Diversity and Inclusion: An International Journal, 29(4), 348363. doi:10.1108/02610151011042402

Panggabean, H., Tjitra, H., \& Murniati, J. (2014). Kearifan Lokal Keunggulan Global : Cakrawala Baru di Era Globalisasi. Jakarta : Elex Media Komputindo.

Pichler, S., Varma, A., dan Budhwar, P. (2012). Antecedents and consequences of the social categorization of expatriates in India. The International Journal of Human Resource Management, 23( 5), 915-927.

Subandi, M.A. (2009). Psikologi Dzikir : Studi Fenomenologi Pengalaman Transformasi Religius. Yogyakarta : Pustaka Pelajar

Tajfel, H. (1982). Social Psychology of Intergroup Relations. Annual Review of Psychology, 33, 1-39.

Triandis, H.C. dan Bhawuk, D.P.S. (1997). Culture Theory and the Meaning of Relatedness. Dalam Earley, P.C. dan Erez, M. (Ed.). New Perspectives on International Industrial/Organizational Psychology. San Fransisco : The New Lexington Press.

Weech-Maldonado, R., Dreachslin, J. L., \& Kathryn, H. (2002). Racial/Ethnic Diversity Management and Culture Competency: The Case of Pennsylvania Hospital. Journal of Healthcare Management, 47(2), 111. 